\title{
MEDIASI KEPUASAN KERJA DALAM MEMPENGARUHI ANTARA KEPEMIMPINAN TERHADAP KINERJA KARYAWAN (Studi Pada Karyawan SDM PDAM Bandarmasih Banjarmasin)
}

\author{
Aida Vitria \\ vitriaaida@gmail.com \\ Rahmi Widyanti \\ rahmiwidyanti@yahoo.com
}

Fakultas Ekonomi Universias Islam Kalimantan MAB Banjarmasin

\begin{abstract}
Banyak faktor yang mempengaruhi kinerja karyawan, yaitu lingkungan kerja, budaya organisasi, kepemimpinan dan kepuasan kerja. pada PDAM Bandarmasih terlihat adanya gejala penurunan kinerja pada sebagian besar karyawan, jika dilihat dari tingkat kehadiran karyawan. Karyawan yang belum mencapai target minimal kehadiran $85 \%$ dalam satu semester semakin bertambah.

Tujuan penelitian ini adalah untuk mengetahui dan menganalisis pengaruh kepemimpinan dan kepuasan kerja terhadap kinerja karyawan PDAM Bandarmasih kota Banjarmasin.

Penelitian ini merupakan penelitian kuantitatif yang akan mengeksplorasi pengaruh antara variabel bebas dengan variabel terikat. Data penelitian ini dikumpulkan dengan angket dari 32 orang responden. Kemudian diuji dengan menggunakan PLS (Partial Least Square).

Hasil penelitian menunjukkan terdapat pengaruh yang signifikan antara kepemimpinan terhadap kepuasan kerja, berpengaruh signifikan antara kepemimpinan terhadap kinerja karyawan. Terbukti berpengaruh signifikan antara kepuasan kerja terhadap kinerja karyawan.
\end{abstract}

Keywords: Job satisfaction, Leadership and Performance

PENDAHULUAN

Kinerja karyawan sangat diperlukan untuk dapat meningkatkan keunggulan bersaing suatu perusahaan (Potter, 1996). Banyak faktor yang dapat mempengaruhi kinerja karyawan, di antaranya adalah kemampuan, pengalaman, tingkat pendidikan, sistem karir (Dessler, 2007). Selain itu faktor yang dapat mempengaruhi kinerja karyawan adalah lingkungan kerja, budaya orgnisasi Menurut Robbins (2006) "seorang dengan tingkat kepuasan yang tinggi 
mempunyai sikap positip terhadap pekerjaan. Hubungan kepuasan kerja dan kinerja dapat dijelaskan dengan pernyataan bahwa seorang pekerja yang berbahagia adalah seorang pekerja yang produktif. Pernyataan ini mengandung arti bahwa kepuasan kerja karyawan akan meningkatkan kinerja. Selanjut nya menurut Robbins (2006) dari analisis yang dilakukan terhadap 68 penelitian dan melibatkan 35.282 responden, ditemukan adanya hubungan yang signifikan dan kuat antara kepuasan kerja dengan kinerja karyawan. Oleh karenanya kebanyakan ahli menyatakan bahwa kepuasan kerja merupakan peramal (predictor) dari kinerja.

Berdasarkan studi pendahul uan pada PDAM Bandarmasih terlihat adanya gejala penurunan kinerja pada sebagian besar karyawan, jika dilihat dari tingkat kehadiran karyawan. Karyawan yang belum mencapai $\mathrm{t}$ arget minimal kehadiran $85 \%$ dalam satu semester semakin bertambah. Data kehadiran karyawan dimonitor dengan menggunakan sidik jari pada saat masuk dan keluar kerja.

Tujuan penelitian ini adalah untuk mengetahui dan menganalisis pengaruh kepemimpinan dan kepuasan kerja terhadap kinerja karyawan PDAM Bandarmasih kota Banjarmasin.

\section{TINJAUAN PUSTAKA}

\section{Pengertian Kepuasan Kerja}

Menurut Robbins (2006) "s eorangdengan tingkat kepuasan yang tinggi mempunyai sikap positif terhadap pekerjaan. Hubungan kepuasan kerja dan kinerja dapat dijelaskan dengan pernyataan bahwa seorang pekerja yang berbahagia adalah seorang pekerja yang produktif." Pernyataan ini mengand ung arti bahwa kepuasan kerja karyawan akan meningkatkan kinerja. Selanjutnya menurut Robbin (2006) dari analisis yang dilakukan terhadap 68 penelitian dan melibat- 
kan 35.282 responden, ditemukan adanya hubungan yang signifikan dan kuat antara kepuasan kerja dengan kinerja karyawan.

Oleh karenanya kebanyakan ahli menyatakan bahwa kepuasan kerja merupakan peramal (predictor) dari kinerja.

\section{Pengertian Kepemimpinan}

Kepemimpinan lebih dari sekedar seperangkat keterampilan dan keahlian. Kepemimpinan mempunyai kualitas personal halus yang agak sulit dilihat, tetapi sangat berpengaruh.

Pengertian kepemimpinan menurut Malayu Hasibuan, 2006:170 adalah :

"cara seorang pemimpin
mempengaruhi perilaku
bawahan, agar mau bekerja
sama dan bekerja secara
produktif untuk mencapai
tujuan organisasi".

Kepemimpinan didefinisikan juga oleh Terry, George R (Kartini Kartono, 2005: 57) yaitu :

"kegiatan mempengaruhi orang-orang agar mereka suka berusaha mencapai tujuantujuan kelompok".

Berdasarkan

beberapa pengertian kepemimpinan yang dikemukakan oleh beberapa ahli diatas, dapat disimpulkan bahwa kepemimpinan adalah suatu kegiatan untuk mempengaruhi orang lain dan merubah perilaku untuk mencapai tujuan bersama.

\section{Pengertian Kinerja Karyawan \\ Dalam rangka mempertemu-} kan kebutuhan socioemotional dan benefit yang didapatkan dari usaha peningkatan kinerja, karyawan membentuk keyakinan umum mengenai sejauh mana organisasi menilai kontribusi mereka dan peduli pada kesejahteraan mereka.

Sikap yang dihasilkan dari kepuasan kerja karyawan terhadap organisasi meliputi peningkatan kinerja dan penurunan prilaku menarik diri dari pekerjaan seperti ketidakhadiran (absenteeism) dan keluar masuk (turnover). 
Menurut Kinicki \& Kreitner meninggalkan organisasi.

(2003) menyatakan bahwa: "individu

dengan tingkat kepuasan

Berdasarkan pendapat

kerja yang tinggi akan memiliki

di atas dapat dinyatakan bahwa

sikap positif terhadap pekerjaannya.

seorang pegawai apabila ia memiliki

Sebaliknya individu dengan tingkat

kepuasan kerja maka kinerjanya

kepuasan kerja yang rendah,

akan meningkat, memiliki kepuasan

cenderung untuk memiliki sikap

kerja maka kinerja akan meningkat,

negatif terhadap pekerjaannya"

karena jika ia puas maka ia akan

Hal ini berarti bahwa individu

mempunyai sikap yang positif dengan tingkat kepuasan kerja yang

terhadap pekerjaannya, ingin tinggal

tinggi, secara emosional akan lebih

serta terlibat dalam kegiatan yang

terikat pada organisasi tempatnya

ada, memiliki keterikatan emosi dan

bekerja atau merasa memiliki

kepedulian yang tinggi terhadap

kewajiban moral untuk tetap tinggal

dalam

organisasi.

Akan

organisasinya. Dengan adanya

tetapi individu dengan tingkat

kepuasan

kerja,

maka

kepuasan kepuasan kerja yang

pegawai akan merasa puas dengan rendah terpaksa tetap tinggal pekerjaannya dan kinerjanya dapat di organisasi karena adanya ditingkatkan.

pemikiran bahwa dirinya akan

Berdasarkan uraian di atas mengalami kerugian bila ebagai berikut:

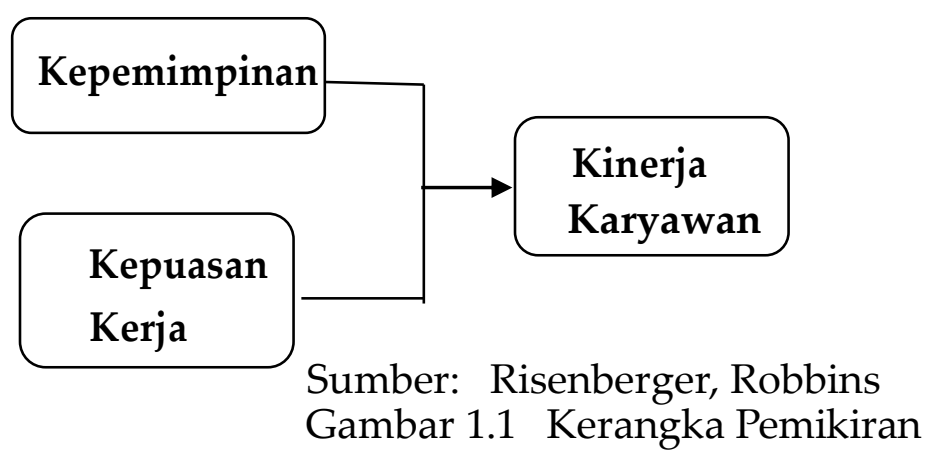




\section{Hipotesis Penelitian}

Sesuai dengan kerangka pemi kiran di atas, maka hipotesis penel itian ini dirumuskan sebagai berikut: Kepemimpinan dan Kepuasan Kerj berpengaruh terhadap Kinerja Karyawan.

\section{METODE PENELITIAN}

Pendekatan yang digunakan dalam penelitian ini adalah pendekatan kuantitatif. Tujuan penelitian ini adalah untuk mengetahui hubungan maupun pengaruh variabel-variabel bebas terhadap variabel terikat. Oleh karena itu dapat dikatakan bahwa jenis penelitian ini adalah penelitian eksplanasi. Menurut Singarimbun dan Effendy (2007;3) bahwa penelitian eksplanasi adalah suatu penelitian yang menjelaskan hubungan maupun pengaruh antara variabel-variabel bebas dengan variabel terikat dengan cara mengajukan hipotesis.

Penelitian ini akan dilakukan di PDAM Bandarmasih Jalan
Jenderal Achmad Yani km. 1,5 Banjarmasin. Populasi dalam penelitian ini adalah seluruh karyawan pada departemen SDM PDAM Bandarmasih di Kota Banjarmasin yang berjumlah 32 orang, sedangkan penarikan sampel dalam penelitian ini tidak dilakukan penarikan sampel karena unit analisis dalam penelitian ini adalah semua karyawan pada departemen SDM yang dijadikan sebagai responden. Penelitian ini merupakan penelitian survey.

3. Pengujian hipotesis

Sesuai dengan tujuan penelitian ini, teknik analisis data yang digunakan adalah menggunakan uji pengaruh dengan menggunakan analisis regresi berganda.

$\mathrm{Y}=\mathrm{B}_{1} \mathrm{X}_{1}+\mathrm{B}_{2} \mathrm{X}_{2}+\mathrm{B}_{3} \mathrm{X}_{3}+\mathrm{e}$

Keterangan:

$\mathrm{Y}=$ Variabel terikat

$\mathrm{X}_{1} \mathrm{X}_{2} \mathrm{X}_{3}=$ Variabel bebas

$\mathrm{B}_{1} \mathrm{~B}_{2} \mathrm{~B}_{3}=$ Koefisien regresi

$\mathrm{e}=$ standar error 
HASIL PENELITIAN DAN

PEMBAHASAN

Karakteristik Responden

Penelitian ini telah menyebarkan sebanyak 32 Kuesioner pada karyawan departemen SDM. Sebanyak 32 kuesioner yang kembali, dan ini berarti tingkat respon dari responden adalah sebesar $100 \%$. Tingkat respon ini dapat dikatakan tinggi karena mencapai 100\%. Karakteristik responden dapat dijelaskan sebagai berikut :

Usia Responden

Usia dapat menunjukkan tingkat kematangan individu dalam berfikir dan berperilaku dalam organisasi. Usia responden di PDAM Bandarmasih Departemen SDM di Kota Banjarmasin bervariasi mulai dari usia terendah yaitu 32 tahun dan tertinggi 52 tahun.

Pada rentang usia tersebut adalah usia yang memiliki pengalaman kerja yang cukup lama untuk menjadi seorang karyawan dan masih termasuk pada usia produktif. Pada usia produktif tersebut karyawan bagian SDM memiliki masih ketrampilan yang tinggi termasuk diantaranya kecepatan, kecekatan, kekuatan, dan profesionalismenya dalam menjalani profesinya sebagai karyawan bagian SDM.

Sebaran jenis kelamin responden di departemen SDM pada PDAM Bandarmasih di Kota Banjarmasin. Dapat menjelaskan bahwa kebanyakan responden adalah berjenis kelamin laki-laki. Meskipun tidak ada perbedaan jenis kelamin untuk pekerjaan yang selalu mengutamakan pekerjaan ini, namun dalam hal ini sebagian besar dari profesi sebagian besar dipegang oleh jenis kelamin laki-laki.

Masa kerja responden adalah masa kerja responden di rumah sakit tempatnya bekerja pada saat pengisian data. Komposisi masa kerja responden menunjukkan berapa lama responden bekerja di rumah sakit tempat sekarang responden bekerja. Masa kerja 
terendah yang dimiliki responden adalah 2 tahun, sedangkan masa kerja tertinggi adalah 29 tahun. Masa kerja responden yang terbanyak adalah pada rentang 12 tahun sampai dengan 17 tahun, berikutnya adalah masa kerja lebih dari 6 tahun sampai dengan 11 tahun. Hal ini menunjukkan bahwa responden memiliki pengalaman kerja yang cukup tinggi di perusahaan tersebut.

\section{Analisis Deskriptif}

\section{Kepemimpinan}

Kepemimpinan diartikan sebagai persepsi karyawan terhadap hubungannya dengan organisasi. Dalam variabel Kepemimpinan ini terdapat enam indikator yang digunakan sebagai parameter untuk mengukur variabel Kepemimpinan yaitu; Kepemimpinan Pengarah $\left(\mathrm{X}_{1.1}\right)$, kepemimpinan pendukung $\left(\mathrm{X}_{1.2}\right)$, kepemimpinan partisipatif $\left(\mathrm{X}_{1.3}\right)$, berorientasi prestasi $\left(\mathrm{X}_{1.4)}\right.$, berorientasi pengakuan $\left(\mathrm{X}_{1.5}\right)$, dan penghargaan (reward) $\left(\mathrm{X}_{1.6}\right)$. Persepsi responden secara umum pada variabel Kepemimpinan ini berhasil mengungkapkan bahwa responden yang dalam hal ini memiliki profesi sebagai dokter memiliki keyakinan bahwa pihak manajemen rumak sakit memiliki kepedulian, tanggung jawab legal, moral dan finansial atas kontribusi yang telah diberikan oleh karyawannya. Hal ini terlihat pada nilai rata-rata total yang dihasilkan oleh variabel ini adalah sebesar 4.04 yang berarti dalam skor yang baik.

\section{Kepuasan Kerja}

Kemampuan profesional karyawan perusahaan bagian SDM untuk memobilisasi sumber daya yang dibutuhkan untuk dapat menggunakannya agar mendapatkan pekerjaan yang dibutuhkan untuk memenuhi tujuan dalam pekerjaan tersebut tertuang dalam kepuasan kerja yang diperolehnya. Dalam variabel pemberdayaan kerja profesional ini terdapat enam indikator yang digunakan sebagai parameter untuk mengukur variabel pemberdayaan kerja profesional yaitu; Pekerjaan itu 
sendiri $\left(\mathrm{Y}_{1.1}\right)$, sesama rekan kerja $\left(\mathrm{Y}_{1.2}\right)$, penghargaan yang diperoleh $\left(\mathrm{Y}_{1.3}\right)$, sistem reward $\left(\mathrm{Y}_{1.4}\right)$, dan kesempatan promosi ( $\left.\mathrm{Y}_{1 . .5}\right)$.

Persepsi responden secara umum pada kepuasan kerja profesional mengungkapkan bahwa akses-akses yang dibutuhkan oleh karyawan perusahaan bagian personalia tempatnya bekerja dalam hal memobilisasi berbagai sumberdaya yang dibutuhkan telah didapatkan dengan baik untuk tujuan pekerjaan sesuai dengan profesinya sebagai karyawan. Hal tersebut nampak pada nilai rata-rata total yang dihasilkan variabel ini adalah sebesar 4.04 yang berarti baik.

\section{Kinerja Karyawan $\left(\mathrm{Y}_{2}\right)$}

Dalam kinerja karyawan ini terdapat tiga indikator yang digunakan sebagai parameter untuk mengukur variabel kinerja karyawan yaitu; jumlah pekerjaan yang dapat diselesaikan $\left(\mathrm{Y}_{2.1}\right)$, mutu pekerjaan yang dihasilkan $\left(\mathrm{Y}_{2.2}\right)$, dan ketepatan waktu dalam menyelesaikan pekerjaan $\left(\mathrm{Y}_{2.3}\right)$.

Persepsi responden secara umum pada variabel kinerja karyawan berhasil mengungkapkan bahwa responden memiliki keterikatan dengan organisasi perusahaan. Hal tersebut nampak pada nilai rata-rata total yang dihasilkan variabel ini adalah sebesar 4.074 yang berarti baik.

\section{Hasil Pengujian Asumsi \\ Analisis PLS}

Analisis PLS memiliki asumsi yang penting, yaitu hubungan linier antar variabel di dalam model struktural (inner model), biasanya disebut asumsi linieritas. Pengujian asumsi linieritas dilakukan dengan metode Curve Fit, dihitung dengan bantuan software SPSS, hasilnya disajikan pada Tabel 1. Rujukan yang digunakan adalah prinsip parsimony, yaitu bilamana seluruh model yang digunakan sebagai dasar pengujian signifikan atau nonsignifikan berarti model dikatakan linier. 
Tabel 1

Hasil Pengujian Asumsi Linieritas

\begin{tabular}{|c|c|c|c|}
\hline Variabel Bebas & Variabel Terikat & $\begin{array}{c}\text { Hasil Pengujian } \\
(\alpha=0,05)\end{array}$ & Keterangan \\
\hline $\begin{array}{l}\mathrm{X} 1= \\
\quad \begin{array}{l}\text { Kepemimpin } \\
\text { an }\end{array}\end{array}$ & $\begin{aligned} \mathrm{Y} 1= & \text { Kepuasan } \\
& \text { Kerja }\end{aligned}$ & $\begin{array}{l}\text { Model linier } \\
\text { signifikan }\end{array}$ & Linier \\
\hline $\begin{array}{l}\mathrm{X} 1= \\
\quad \begin{array}{l}\text { Kepemimpin } \\
\text { an }\end{array}\end{array}$ & $\begin{aligned} \mathrm{Y} 2= & \text { Kinerja } \\
& \text { karyawan }\end{aligned}$ & $\begin{array}{l}\text { Model linier } \\
\text { signifikan }\end{array}$ & Linier \\
\hline $\begin{array}{c}\mathrm{Y} 1=\text { Kepuasan } \\
\text { Kerja }\end{array}$ & $\begin{aligned} \mathrm{Y} 2= & \text { Kinerja } \\
& \text { Karyawan }\end{aligned}$ & $\begin{array}{l}\text { Model linier } \\
\text { signifikan }\end{array}$ & Linier \\
\hline
\end{tabular}

Sumber: data diolah (Desember, 2017)

Berdasarkan

perhitungan indikator dari variabel Kepemimpinan $\left(\mathrm{X}_{1}\right)$ yang berperan sebagai pengukur terkuat adalah kehormatan $\quad\left(\mathrm{X}_{1.4}\right), \quad$ variabel Kepuasan Kerja $\quad\left(\mathrm{Y}_{1}\right)$ adalah pekerjaan itu sendiri $\left(\mathrm{Y}_{1.1}\right)$, dan untuk variabel Kinerja Karyawan $\left(\mathrm{Y}_{2}\right)$ adalah ketepatan waktu dalam bekerja $\left(\mathrm{Y}_{2.3}\right)$. Kondisi empiris semua variabel menurut persepsi responden adalah cukup baik, yaitu dengan rerata skor diatas 4 . Indikator pada variabel kepemimpinan yang dipersepsikan paling baik oleh responden adalah pengakuan $\left(X_{1.5}\right)$. Sistem Reward (Y.4) adalah indikator yang dipersepsikan paling baik pada variabel Kepuasan kerja, sedangkan ketepatan waktu dalam bekerja ( $\left.\mathrm{Y}_{2.3}\right)$ adalah indikator yang dipersepsikan paling baik pada variabel Kinerja Karyawan

\section{Hasil Pengujian Hipotesis}

Pengujian hipotesis dilakukan dengan t-test pada masing-masing jalur pengaruh langsung secara parsial. Tabel 2 menyajikan hasil pengujian hipotesis pengaruh langsung. 
Tabel 2

Hasil Pengujian Hipotesis

\begin{tabular}{|c|c|c|c|c|}
\hline $\begin{array}{c}\text { Variabel } \\
\text { Bebas }\end{array}$ & Variabel Terikat & $\begin{array}{c}\text { Koefisien } \\
\text { Jalur }\end{array}$ & $\begin{array}{c}\text { p- } \\
\text { value }\end{array}$ & Keterangan \\
\hline $\begin{aligned} \mathrm{X} 1= & \\
& \begin{array}{l}\text { Kepemim } \\
\text { pinan }\end{array}\end{aligned}$ & $\begin{array}{c}\text { Y1 = Kepuasan } \\
\text { Kerja }\end{array}$ & 0.574 & $\begin{array}{c}< \\
0,001\end{array}$ & Signifikan \\
\hline $\begin{array}{l}\mathrm{X} 1= \\
\quad \begin{array}{l}\text { Kepemim } \\
\text { pinan }\end{array}\end{array}$ & $\begin{aligned} \mathrm{Y} 2= & \text { Kinerja } \\
& \text { Organisasi }\end{aligned}$ & 0.360 & $<0.057$ & Signifikan \\
\hline $\begin{aligned} \mathrm{Y} 1= & \text { Kepuasan } \\
& \text { Kerja }\end{aligned}$ & $\begin{aligned} \mathrm{Y} 2= & \text { Kinerja } \\
& \text { Organisasi }\end{aligned}$ & 0.545 & $<0.001$ & Signifikan \\
\hline
\end{tabular}

Sumber: data diolah (Desember, 2017)

Hasil pengujian hipotesis jalur-jalur pengaruh langsung juga dapat dilihat pada gambar diagram jalur sebagai berikut:

\section{Gambar 2}

\section{Diagram Jalur Pengaruh Langsung}

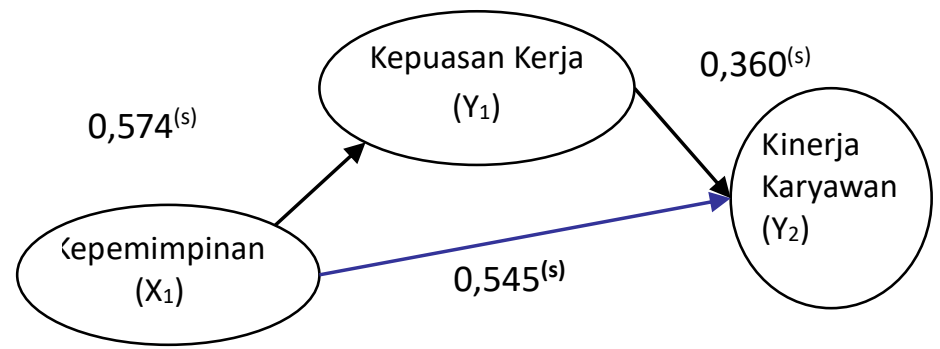

Keterangan: $\mathrm{s}=$ signifikan

Berdasarkan hasil pengujian

hipotesis secara statistik pada tabel

5.1 dan Gambar 2, maka didapatkan sebagai berikut:

1. Kepemimpinan $\left(\mathrm{X}_{1}\right)$ berpengaruh signifikan terhadap kepuasan Kerja $\quad\left(\mathrm{Y}_{1}\right)$. Hasil analisis menggunakan PLS diporoleh koefisien jalur sebesar 0,574 dengan $\mathrm{p}<0,001$, sehingga dikatakan signifikan. Mengingat koefisien jalur bertanda positif, dapat diartikan bahwa semakin baik Kepemimpinan yang dirasakan oleh pegawai, maka 
Kepuasan Kerja semakin meningkat.

2. Kepemimpinan $\left(\mathrm{X}_{1}\right)$ berpengaruh signifikan terhadap Kinerja Karyawan $\left(\mathrm{Y}_{2}\right)$. Hasil analisis menggunakan PLS diperoleh koefisien jalur sebesar $\quad 0,360$ dengan $\mathrm{p}=0,057$, sehingga dikatakan signifikan. Hal ini dapat diartikan bahwa baik buruknya Kepemimpinan $\left(X_{1}\right)$ berpengaruh terhadap Kinerja Karyawan $\left(\mathrm{Y}_{2}\right)$.

3. Kepuasan Kerja $\left(\mathrm{Y}_{1}\right)$ berpengaruh signifikan terhadap Kinerja Karyawan $\left(\mathrm{Y}_{2}\right)$. Hasil analisis menggunakan PLS diperoleh koefisien jalur sebesar 0,545 dengan $\mathrm{p}<0,001$, sehingga dikatakan signifikan. Mengingat koefisien jalur bertanda positif, dapat diartikan bahwa semakin baik Kepuasan kerja, maka Kinerja Karyawan semakin meningkat.

\section{KESIMPULAN}

1. Kepemimpinan ditemukan mampu meningkatkan kepuasan kerja karyawan. Kepemimpian yang dipersepsikan sebagai bentuk hubungan antara atasan dan bawahan yang tinggi, dapat meningkatkan kepuasan kerja karyawan.

2. Kepemimpinan ditemukan mampu memberikan peningkatan terhadap kinerja karyawan secara langsung. Meskipun kepemimpinan dan kinerja karyawan dipersepsikan baik oleh karyawan, hal tersebut mampu meningkatkan kinerja karyawan dikarenakan karyawan departemen SDM melaksanakan tugas dengan dengan baik.

3. Kepuasan Kerja dapat meningkatkan kinerja karyawan. Hal ini mengindikasikan bahwa menyukai pekerjaan dan pemberian reward akan dapat menimbulkan kinerja karyawan yang semakin tinggi. 
Peningkatan kepuasan kerja melalui pekerjaan yang menyenangkan dan pemberian reward menjadi tolok ukur pertukaran untuk peningkatan kinerja karyawan.

\section{DAFTAR PUSTAKA}

Almutairi, Dhaifallah Obaid 2013, The Relationship between Leadership Styles and Organizational

Commitment: A Test on Saudi Arabian Airline, World Review of Business Research Vol. 3. No. 1. January 2013 Issue. Pp. $41-51$.

Allen, D.G, Lynn M. Shore, \& Rodger W. Griffeth. 2003. The Role of Perceived Organizational Support and Supportive Human Resource Practices in the Turnover Process. Journal of Management 29 (1) 99-118.

Arikunto, Suharsimi, 2006, Metode Penelitian Sosial, Ghalia Indonesia, Jakarta

Ismail Azman, Hasan Al-Banna Mohamed, Ahmad Zaidi Sulaiman, Mohd Hamran Mohamad, Munirah Hanim Yusuf, 2011, An Empirical Study Of The Relationship Between Transformational Leadership, Empowerment
And Organizational Commitment, Business and Economics Research Journal Volume 2 . Number 1 . 2011, pp. 89-107

Becker. H. 1990. Notes on the concepts of commitment. American Journal of Sociology. Vol 66, pp. 32-42

Dansereau, F., Graen, G. and Haga, W.J. 1975. A vertical dyad linkage approach to leadership within formal organizations: a longitudinal investigation of the role making process. Organizational Behavior and Human Performance, Vol. 13, pp. $46-78$

DeCicco, Julie, Heather Laschinger, and Michael Kerr. 2006. Perception of Empowerment and Respect, Effect on Nurses' Organizational Commitment in Nursing Homes. Journal of Gerontological Nursing. 32 (5): 49-56

Ferdinand, Augusty, 2006, Metode Penelitian: Teori dan Aplikasi, BP Undip, Semarang

Fiedler, Fred E. 1967. A Theory of Leadership Effectiveness. McGraw Hill. New York.

Gibson, J.L., Ivancevich, J.M., Donnelly, J.H. 1996. Organisasi: Perilaku, Struktur, 
Proses, Terjemahan Nunuk Adiarni. Editor Lyndon Saputra. Jakarta: Penerbit Binarupa Aksara.

Hollander, E.P. and Offerman, L.R. 1990. Power and leadership in organizations: relationships in transition, American Psychologis, 45 (3): 179-189.

House, Robert J. and Terence R. Mitchell. 1974. Path-Goal Theory Of Leadership. Journal of Contemporary Business Autumm. Pp..81-97

Koesmono, H.Teman. 2007. Pengaruh Kepemimpinan Dan Tuntutan Tugas Terhadap Komitmen Organisasi Dengan Variabel Moderasi Motivasi Perawat Rumah Sakit Swasta Surabaya. Jurnal Manajemen dan Kewirausahaan. Vol 9, No. 1, Maret 2007:30-40

Lee, Jean. 2005. Effects of Leadership and Leader-Member Exchange on Commitment. Leadership $\mathcal{E}$ Organization Development Journal. Vol. 26 No. 8 pp. 655-672.

Luthans, F. 2006. Organizational Behavior, Ninth Edition, Boston: McGraw Hill.

Mathieu, J. E., \& Zajac, D. 1990 A review and meta-analysis of the antecedents, correlates, and consequences of organizational commitment, Psychological Bulletin, 108: 171194.

Meyer, J. P., \& Allen, N. J., 1997, Commitment in the workplace. Thousand Oaks, CA: Sage.

Mowday, R., Porter, L., \& Steers, R.. 1982. Employee-organization linkages: The psychology of commitment, absenteeism, and turnover, New York: Academic Press.

Porter, L.W.,Crampon, W. \& Smith, F. 1976. Organizational commitment and managerial turnover: A longitudinal study. Organizational Behavior and Human Performance, 15, 8798.

Robbins, Stephen P. 2006. Perilaku Organisasi. Edisi Kesepuluh.Molan, Benyamin (penerjemah). Jakarta: Prenhallindo.

Schermerhorn, J, R., Jr., Hunt, J.G. and Osborn, R.N. 1998. Basic Organizational Behavior. $2^{\text {nd }}$ ed. New York: John Wiley.

Shore, L. M., \& Shore, T. H. 1995. Perceived organizational support and organizational justice. In R. Cropanzano \& K. Kacmar (Eds.), Organizational politics, justice, and support: 
149-164. Westport, CT: Quorum.

Spector, P.E. 1986. Perceived control by employees : a metaanalysis of studies concerning autonomy and participation at work, Human Relations, 39 (1): 1005-1016

Wilkinson, A. 1998b. Empowerment: Theory and Practice, Personnel Review, Vol. 27 No. 1, 1998, pp. 40-56, (C) $M C B$ University Press, 0048-3486

Winkler, Ingo. 2010. Contemporary Leadership Theories, Contributions to Management Science. Publisher: Springer-Verlag Berlin Heidelberg.

Yukl, Gary. 2007. Leadership in Organization, Fifth Edition. Supriyanto, Budi (penerjemah). Kepemimpinan Dalam Organisasi. PT. Indeks Indonesia. Jakarta. 